\title{
Editorial
}

\section{Lessons from Obama Care}

The United States of America (USA) has tried to revolutionize healthcare delivery to its citizens by ushering in Obama care (The Patient Protection and Affordable Care Act). It is important to analyze and understand why a seemingly populist scheme with all noble intentions is facing so much of hurdle in implementation. The understanding of the nuances will provide insight to the planners of healthcare policy to deliberate extensively before deciding on any similar policy.

Presently in US, there are about 32 to 50 million people who do not have health insurance. In case of hospitalization, they are often not in a position to foot the bill. Obama care has been designed to provide quality care and increase the accessibility and affordability of health insurance to the general populace of USA. In exchange, most people, who can afford to, must obtain health coverage by 2014 or pay a per month fee. The law eliminates pre-existing conditions, stops insurance companies from dropping you when you are sick, protects against gender discrimination, expands free preventative services and health benefits, expands medicaid and CHIP (Children's Health Insurance Programme), mandates larger employers insure employees, creates a marketplace for subsidized insurance providing tens of million individuals, families and small businesses with free or low-cost health insurance, and decreases healthcare spending and the deficit.

The highlights of Affordable Care Act (ACA) are as follows:

Most people who currently have health insurance can keep it. It creates states-based health insurance exchange marketplaces where federally regulated and subsidized insurances are available. Young adults can stay on their parents' plan until 26. It requires that all plans cover 10 essential health benefits such as outpatient care, emergency services, inpatient care, maternity services, mental health services, rehabilitative services, lab services, pediatric services, precription drugs, etc. Preventive services are free.

If health coverage is not there, then new health insurance plan can be bought from private insurance plan. Open enrollment in the health insurance marketplace till March 31st, 2014. If you do not obtain coverage or an exemption by 1st January 2014, you must pay a per-month fee on your federal income tax return for every month you are without health insurance.

The cost of marketplace health insurance works on a sliding scale. Those who make less, pay less. American making less than $\$ 45,960$ as individual or $\$ 94,200$ as a family of four may be eligible for premium tax credits through the marketplace. If you are able to get qualified health insurance through your employer, you would not be able to receive marketplace tax credits unless the employer does not cover at least $60 \%$ of your premium cost, does not provide quality insurance or provides insurance that exceeds $9.5 \%$ of your families income.

Up to $82 \%$ of nearly 16 million uninsured young US adults will qualify for federal subsidies or medicaid through the marketplace. The ACA does away with pre-existing conditions and gender discrimination so these factors will no longer affect the cost of your insurance on or off the marketplace. Health coverage cannot be denied based on health status. Health insurers cannot place lifetime limits on your coverage. As of 2014, annual limits are eliminated as well.

All new plans sold on or off the marketplace must include a wide range of new benefits, including wellness visits and preventive tests and treatments at no additional out-of-pocket cost. All full-time workers who work for companies with over 50 employees must be offered job-based health coverage by 2015. Employers who do not offer coverage will pay a per-employee fee.

Small businesses with under 50 full-time employees can use a part of the marketplace called the SHOP (small business health options program) to purchase group health plans for their employees. Small businesses with under 25 full-time employees can use the marketplace to purchase subsidized insurance for their employees.

Companies must spend at least $80 \%$ of premiums on providing actual medical services. If they spend it on advertizing or executive salaries, they have to pay the excess back to policyholders.

\section{Challenges}

The various hurdles that the US administration is facing are as follows:

Increased coverage may actually raise the overall healthcare costs in the short-term as preventive care and screening tests will add up to the cost. To make it work financially, millions of uninsured must sign up for medical coverage, especially younger, healthier people, and that is very much in doubt right now. 
Obama care's long-term nursing plan for the elderly has been repealed after the administration concluded that it was financially unworkable. About half the states have decided against creating their own health insurance exchanges, a central pillar in the system, letting the federal government run the exchanges instead.

With so many Americans out of work, it is difficult to justify forcing people to buy insurance they do not want or their present priorities are different. Small businesses will reduce their workforce below the 50-worker level or cut part-time hours to escape the mandate altogether.

Obama care purports to finance itself with taxes only on upper-income Americans. The revenues from these taxes will be inadequate to sustain this scheme. This mode of finance will corrode all political incentive for cost control. Not many voters will deprive themselves of a benefit to save somebody else money.

No system is perfect, but the Affordable Care Act aims to reform the American Health Care system toward the favor of the people and away from the favor of corporations and stockholders. Obama care's many provision give new patient protections in dealing with insurance companies and in return mandates that everyone who can afford to must obtain health insurance by 2014 or pay a fee.

As it is evident from the above, it is imperative that, in any country, the government must plan its long-term policies and programs taking all stakeholders into confidence. It is important to understand that taxpayer's money should be spent so as to benefit the maximum clientele.

Editors 